\title{
AN ECONOMETRIC ANALYSIS OF THE EFFECTS OF REDUCTIONS IN FOOD STAMP BENEFITS AND CASH-OUT IN PUERTO RICO
}

\author{
Marianne T. Hill and Alan T. Udall*
}

\section{Introduction}

Recent reductions in food stamp benefits have had a substantial impact on the Puerto Rican economy and on the nutritional status of the poor: funding levels dropped from over $\$ 900$ million in the 1981 federal fiscal year to a nutrition assistance block grant of $\$ 825$ million for subsequent years. This grant finances the $\$ 799$ million Nutrition Assistance Program and \$26 million in agricultural and nutrition education projects. In order to reduce administrative costs and thus minimize the necessary reduction in benefits, the Government of Puerto Rico shifted from a coupon system to a check system (the "cashout") at the time this program was implemented.

The magnitude of the impact of these cuts on the Puerto Rican economy can only be understood in light of the importance of food stamps in supplementing family incomes and improving nutrition in Puerto Rico. Puerto Rico's per capita personal income, at $\$ 3,918$ in FY 1982 , is considerably lower than that of the poorest state, and food stamp benefits, the largest transfer program after social security, account for over 7 percent of personal income. Approximately 50 percent of families receive food stamps.

The Economic and Financial Council of the Governor has estimated an econometric model of the Puerto Rican economy which makes possible statistical studies of changes in the economy. The model, which consists of approximately 100 structural equations and analyzes over 200 variables, is sufficiently detailed to permit examination of several categories of consumption, employment, and imports as well as gross product and income distribution.

This study uses the Council's model to examine several questions regarding the impact of the food stamp program, the reduction in funding, and the switch to checks from stamps. Section two presents the model and the methodology used for simulations of the effects of funding reductions and of the switch from food stamps to checks. Section three gives the results of policy simulations estimating the effect of reduced funding levels, without allowing for any possible change in consumer behavior that might occur as a result of the cash-out of the food stamp program. Section four concentrates on the effects of cash-out. Simulations of the probable effects of the change to checks are presented and evaluated in light of current economic literature.

\section{The Model and Methodology}

The original basis of the Council's model was Jorge Freyre's (1979) econometric model, which was heavily influenced by the Wharton model of the U.S. Data are based on the value-added system of national accounting which are calculated by the Puerto Rico Planning Board.

A methodological appendix available from the authors provides detailed information regarding the technical procedures followed. Some of the more important aspects of the model are summarized here, 
The Review of Regional Studies

however. Consumption, investment and government expenditures, as well as net imports are linked in this model via a basic Keynesian expenditure identity.

The total demand of the private sector for consumer goods is found by aggregating consumption functions for several categories of consumer goods including foods, other nondurable goods, consumer durables, and services. Personal consumption is completely endogenous. Income from food stamps enters the consumption functions as an exogenous component of consumers' income, with its real value dependent upon the price index of food in Puerto Rico.

Other major endogenous variables included in the model are imports, exports, government expenditures and revenues, investment and sectoral employment. The private demand for investment goods and government consumption demand include both endogenous and exogenous components. Government investment expenditures are exogenous, while imports are endogenous and exports depend largely on external factors. Sectoral employment and the distribution of income by various categories, such as corporate income and private sector wages, are also simulated by the model. While the structural equations of the model are based on real values, a link to current values is provided by price equations linking Puerto Rican prices to exogenous U.S. prices and other variables.

The effect of food stamps on the economy is traced through the use of a variable in the consumption equations representing income received in the form of food stamp benefits. In addition, food stamp payments are a part of total U.S. transfer payments and affect personal disposable income in some nonconsumption equations as well, such as investment in private housing.

The increase in consumption expenditures made possible by the food stamp program has a significant impact on such items as imports, output of transportation services, employment in commerce, and so on. The output of the agricultural sector and employment in agriculture are positively affected by the program, as would be expected. Full results are presented in the sections which follow.

Several lagged variables enter the equations of the model, which make possible a dynamic simulation of the path of the economy over time. In the forecast simulations presented here the values for the lagged endogenous variables used in solving the system are those predicted by the model and not the actual lagged values.

In order to estimate the effects of the reduction in funding of the food stamp program on the economy as a whole, the model was solved under two different assumptions regarding the levels of funding for the food stamp program: one labeled "Pre-1982 Treatment" and the other "Present Reductions." The funding levels under "Pre-1982 treatment" are those which assume Puerto Rico's continued statelike participation in the food stamp program, while those under "present reductions" are ones presented in the Puerto Rico Social Services budget, reflecting the reduced funding which accompanied the switch to a block grant. Adjustments necessary due to differences in federal and Puerto Rican fiscal years have been made. Results presented in the next section show the projected levels of key economic variables for FY 1983 and FY 1984 under the two alternative funding levels.

Since only changes in levels of economic activity in Puerto Rico are of concern in this study, the accuracy of assumptions made regarding the U.S. economy and levels of investment in the island are not important and will not be reviewed here.

\section{Results of Policy Simulations: Effects of Funding Cuts}

The cuts in food stamp benefits have caused notable drops in several key economic variables, according to the policy simulation results presented in Tables 1 to 4 . However, it should be made clear at the outset that the figures in these tables understate the true changes since some important links between consumption expenditures and output are not captured by the model. Furthermore, the economic changes shown in these tables do not adequately reflect the most important single result of the food stamp cutbacks - the decline in the nutritional status of the poor in Puerto Rico.

Table 1 shows the predicted values of major economic indicators under actual funding levels in comparison with values predicted under funding levels that had been budgeted by the Reagan Administration prior to 1982. Under the latter treatment, we assume that Puerto Rico was appropriated funds at statelike levels. The gross state product, according to these results, will be about one percent lower in real terms in 1984 than it would have been under statelike funding of the food stamp program. Personal income is predicted to fall by 1.9 percent in 1983 and 2.2 percent in 1984 as a result of the reduction in food 
TABLE 1

Estimated Impact on Key Variables of Reduced Funding of Food Stamp Benefits: Simulation Results, FY 1982 to FY $1984^{1}$

\begin{tabular}{|c|c|c|c|c|c|c|c|}
\hline & 1982 & 19 & & 198 & & Percentage & Difference \\
\hline & $\begin{array}{c}\text { Projections } \\
\text { Under Present } \\
\text { Reductions } \\
\end{array}$ & $\begin{array}{c}\text { Projections } \\
\text { Under Pre-1982 } \\
\text { Treatment } \\
\end{array}$ & $\begin{array}{c}\text { Projections } \\
\text { Under Present } \\
\text { Reductions } \\
\end{array}$ & $\begin{array}{c}\text { Projections } \\
\text { Under Pre-1982 } \\
\text { Treatment } \\
\end{array}$ & $\begin{array}{c}\text { Projections } \\
\text { Under Present } \\
\text { Reductions } \\
\end{array}$ & 1983 & 1984 \\
\hline \multicolumn{8}{|l|}{ Gross State Product } \\
\hline Current Dollars & $11,952.10$ & $12,104.10$ & $12,044.60$ & $12,830.31$ & $12,749.05$ & 0.49 & 0.64 \\
\hline 1954 dollars & $3,770.16$ & $3,595.16$ & $3,567.86$ & $3,587.75$ & $3,553.81$ & 0.77 & 0.95 \\
\hline \multicolumn{8}{|l|}{ Gross Domestic Product } \\
\hline Current Dollars & $15,154.51$ & $15,427.25$ & $15,378.43$ & $16,510.79$ & $16,401.70$ & 0.51 & 0.67 \\
\hline 1954 dollars & $4,766.32$ & $4,586.11$ & $4,553.49$ & $4,574.54$ & $4,615.71$ & 0.72 & 0.90 \\
\hline \multicolumn{8}{|l|}{ Personal Income } \\
\hline Current Dollars & $12,159.43$ & $12,461.41$ & $12,234.39$ & $13,196.80$ & $12,919.07$ & 1.86 & 2.15 \\
\hline 1954 dollars & $3,692.13$ & $3,573.52$ & $3,508.21$ & $3,581.45$ & $3,505.83$ & 1.86 & 2.16 \\
\hline \multicolumn{8}{|l|}{ Employment } \\
\hline Thousands Employed & 794.86 & 779.49 & 776.52 & 778.95 & 775.43 & 0.38 & 0.45 \\
\hline \multicolumn{8}{|l|}{ Personal Consumption } \\
\hline Current Dollars & $12,302.58$ & $12,658.24$ & $12,445.68$ & $13,485.70$ & $13,226.46$ & 1.71 & 1.96 \\
\hline 1954 dollars & $3,735.59$ & $3,629.97$ & $3,568.80$ & $3,659.84$ & $3,589.23$ & 1.71 & 1.97 \\
\hline \multicolumn{8}{|l|}{ Government Revenues ${ }^{2}$} \\
\hline Current Dollars & $2,008.55$ & $2,041.23$ & $2,029.10$ & $2,147.29$ & $2,132.14$ & 0.60 & 0.71 \\
\hline \multicolumn{8}{|l|}{ Imports } \\
\hline Current Dollars & $15,310.61$ & $15,776.00$ & $15,607.68$ & $16,977.23$ & $16,778.15$ & 1.08 & 1.19 \\
\hline 1954 dollars & $3,716.00$ & $3,640.99$ & $3,602.24$ & $3,722.36$ & $3,679.37$ & 1.08 & 1.17 \\
\hline
\end{tabular}

1Puerto Rico's fiscal year runs from July 1 to June 30 . Under continued statelike treatment, the food stamp program in Puerto Rico was projected to reach $\$ 965.70$ million in 1983 and $\$ 1,006.40$ million in 1984 (P.R. fiscal year). Under the special block grant, projected food assistance benefits are $\$ 771.9$ million both years. An additional $\$ 26.7$ million is slated for administrative costs, another $\$ 4.6$ million for a nutrition education program, and $\$ 21.8$ million for agricultural production projects.

2Taxes going to general fund.

stamp benefits while consumption drops by 1.7 percent and 2.0 percent in those years. Total employment is expected to decline by .45 percent $(3,520$ jobs) in 1984 , although this is a conservative estimate (see discussion below) and imports, largely from the U.S., will fall by 1.2 percent that year. The reduction in the values of key economic variables is greater in 1984 than in 1983, according to our calculations, because the gap between the original and reduced levels of funding increases and the effect of the 1983 downturn carries over into 1984 .

These projections are based on budget figures showing that nutrition assistance benefits will be $\$ 194$ million lower in 1983 than under pre-1982 treatment and that by 1984 the difference will have widened to $\$ 235$ million. Since total personal income in Puerto Rico is $\$ 12.5$ billion, the projected drops in gross product and consumption, while large, appear quite reasonable.

Turning to Table 2, we now consider the effect on consumption in more detail. In aggregate, total personal consumption falls by 1.7 and 2.0 percent in 1983 and 1984 respectively. The largest decrease is in expenditures on consumer durables, followed by decreases in food expenditures, and other nondurables and services. It is to be expected that, faced with a reduction in income, consumers will postpone purchase of durable items, such as electrical appliances, before cutting back on food purchases or other items of immediate necessity.

Expenditures on food are projected to be $\$ 57$ million lower in 1983 , thus implying that the $\$ 194$ million cut has had a large impact on aggregate food consumption. A comparison of this finding with the results of other studies of the food stamp program are presented in the following section. 


\section{TABLE 2}

Simulated Impact of Cuts in Food Stamp

Benefits on Personal Consumption Expenditures

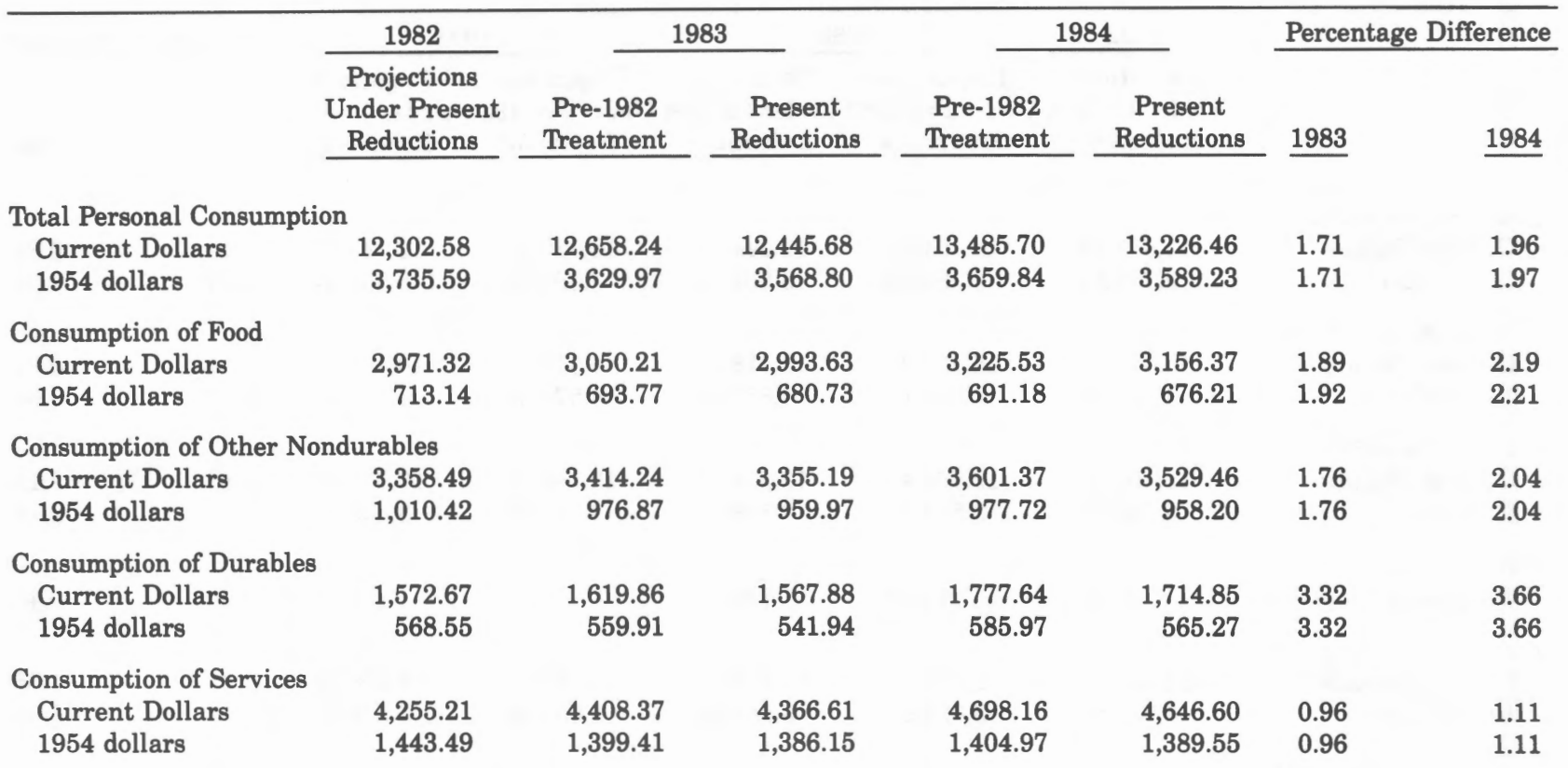

Sectoral employment is also affected by the cuts in food stamp benefits. The large drop in employment in absolute numbers in 1983 is in the government sector, where falling revenues reduce employment by 1,510 . The next largest fall is in services employment, with 460 jobs lost, followed by commerce with 360 persons affected. In agriculture, approximately 170 persons more will be unemployed in 1983 and 260 more in 1984. The agricultural projects funded by the Nutrition Assistance Program will not greatly affect these numbers. The impacts on manufacturing (220 persons), finance (170 persons) and transportation (180 persons) are also sizeable. These numbers are all noticeably higher in 1984 , with total job loss reaching 3,520 .

Imports of goods and services are found to drop sharply in some categories. Overall, imports fall by 1.1 percent in 1983 and 1.2 percent in 1984 . More than half of this decrease is due to falling imports of consumer goods. In 1984, for example, imports of consumer nondurables are projected to decline by $\$ 44$ million and consumer durables by $\$ 37$ million. Services imports decrease by $\$ 47$ million. Most of Puerto Rico's imports are from the U.S. and these declines can be expected to adversely affect U.S. agriculture and export industries.

Estimates for fiscal 1983 show a reduction in total revenues to the Commonwealth General Fund of 0.6 percent as a result of current cuts. The majority of this estimated $\$ 12$ million revenue loss is a result of lower excise tax income as lower disposable income causes reduced consumption expenditures on electrical appliances and other highly taxed items. Personal and corporate taxes are also found to decrease by about 0.5 percent as the feedback effects of reduced consumption cut back on local production and employment. With the exception of the tollgate tax, which is projected exogenously, and a few small sources of revenue, all components of government revenue show even larger drops in 1984, with total loss at $\$ 15$ million.

The reduction in transfer payments and the concomitant percentage increase in the importance of other sources of personal income are reflected in the functional income distributions. Transfer payments as a percent of total personal income fall from 30.1 to 29.0 percent under the impact of the program cuts in 1983. Wages and salaries, and property income become proportionately more important.

In summary, the funding reductions of $\$ 194$ million and $\$ 235$ million for fiscal years 1983 and 1984 have considerable impact on the economy, occasioning drops in personal income and consumption near 
2 percent in 1983 and greater drops in 1984. Imports, largely from the U.S., also fall considerably, and other economic variables including government revenues and employment show noticeable declines. Consumption of food is adversely affected, as would be expected, dropping by $\$ 69$ million or 2.2 percent in 1984. This, however, is an aggregate figure which conceals the distribution of the fall in food consumption. In fact, only families receiving stamps previous to the cuts would be expected to have their food consumption drop significantly, so that drops of 5 percent and more have occurred for many families.

The estimates presented in this section must be treated with caution, and in general should be regarded as underestimates of the actual effects for the following reasons:

1. The model is built on aggregate variables and further disaggregation would be likely to increase the impact of reduced food benefits on production aimed at the local market, since the multipliers for food-related industries have been found to be higher than those for other sectors.

2. The effects of the funding cuts are assumed to begin in FY 1983, with the imposition of the block grant for Puerto Rico. In fact, however, both Puerto Rico and the states experienced some food stamp cuts in the previous fiscal year as well, due to tightened eligibility requirements, and these cuts would have a cumulative impact.

3. In future years, as inflation reduces the purchasing power of Puerto Rico's fixed block grant, the difference between statelike and actual funding levels-and the corresponding effects on income, employment and nutritional status-will grow progressively larger. The difference between FY 1983 and FY 1984 effects gives some idea of how this situation will worsen over time.

These figures, then, show that the funding cuts have seriously adverse nutritional and economic effects on Puerto Rico. Congressional re-examination of the change to the block grant may be warranted.

\section{Probable Impact of the Cash-Out of Food Stamp Benefits on Food and Other Consumption Expenditures}

At present, there exists a considerable literature on the impact of the food stamp program on food expenditures and nutrition [See, for example, Smallwood and Blaylock (1982), Brown, Johnson and Riyek (1982), Nelson and Perrin (1976)]. Recently, there has also been growing interest in the impact of a "cash-out" of the program-that is, a switch from stamps to checks-on recipient behavior. In this section, the findings of other studies are used to place the results of our model simulation in a broader context. At the same time, these studies also provide information regarding the range of possible effects of a cash-out of food stamp benefits. Based on these findings, a simulation of the effect of the cash-out in Puerto Rico is presented.

A key problem in estimating the impact of food stamp benefits on consumption patterns is that of isolating the effect of food stamp income from that of other types of income. Most studies concerned with this question have been cross-sectional analyses of household data. Thus the approach has largely been that of single equation analysis, often employing regression or probit methodology in which several variables are included to control for the various factors influencing family expenditure decisions. Few econometric studies have been done of the aggregate impact of the food stamp program on the U.S. economy. However, Nelson and Perrin (1976) used an adjusted version of the U.S. Department of Commerce's 1967 input-output model to estimate the program's aggregate effect. Their basic approach was to assume that the program effects occurred via a shift in income distribution caused by government taxation and expenditures undertaken in conjunction with the program. The methodology used thus differs considerably from that of the present study. Nonetheless, theoretical and empirical findings from both cross-sectional household studies and aggregate macroeconomic studies are useful in showing the range of acceptable predictions. The wide divergence in results is striking although there is general agreement as to the importance of the program in providing a minimum level of nutrition to low-income families.

Generally, studies both in the U.S. and in Puerto Rico do not indicate any difference in average food expenditures between families at the same income level who receive their income from different sources. That is, participants in the food stamp program appear to spend the same percentage of their income on food as nonparticipants at the same income level.

Consider for example, the study of the effects of cash-out done by Blanchard et al. (1982). A cash-out demonstration was conducted at eight sites across the U.S. among households of the elderly and other 
SSI participants; eight additional sites served as comparison sites in which food stamps continued to be received. Not only were average food expenditures the same for both groups, but the marginal propensity to consume on food out of bonus income was found to be slightly, but not significantly, higher for the recipients of the cash bonus.

Studies of food consumption in Puerto Rico based on the 1977 food consumption survey indicate similar results. Low-income eligible nonparticipants in the food stamp program spent more per capita on food on average than eligible participants. Once adjustments are made to follow for the different characteristics of participants versus nonparticipants, different interpretations of the data are possible. Chai et al. (1982) estimated equations for food expenditure which included independent dichotomous variables for such factors as employment, five years or more of education, type of store for food purchases, and owner-occupied housing, as well as more standard variables such as per capita income, household size, urban versus rural residency, and size of food stamp bonus. Chai et al. found that while average family expenditures may be greater in total among recipients, the marginal propensity to consume on food appeared higher among eligible nonparticipants. This was attributed to the fact that food purchases by participants are less likely to be affected by fluctuations in income than those of nonparticipants, since the food stamp program provides a basic minimum consumption and stamp benefits drop as income rises.

On the other hand, using the same 1977 data, Blanciforti (1982), who did not include the first four independent dichotomous variables mentioned above but added others, came to the opposite conclusion: the marginal propensity to consume (MPC) on food for the food stamp bonus was found to be greater than the MPC for food of cash income. However, Blanciforti excluded 93 percent of 801 eligible participant families from her analysis since their food consumption expenditures were less than the allottment value of the food stamps. According to the usual theoretical framework, these are the only families where a switch from food stamps to checks would be expected to have an effect. The wide range of conclusions and apparently contradictory findings regarding the likely effect of a change from food stamps to a cash bonus is largely due to the theoretical weaknesses of work in this area.

In attempting to estimate the likely impact of the switch from food stamps to checks, then, the Council staff had relatively weak empirical evidence on which to rely. In addition, the switch was not a marginal one, whereas much of the literature deals with marginal change. Therefore, in simulating the effect of cash-out the Council used two different scenarios. In case I, following Chai et al., the switch was assumed not to have any significant impact on food consumption. In case II, figures from Blanciforti estimating a 7 percent impact on the food consumption of a standardized participant-implying a 3.5 percent aggregate drop in food consumption with a shift to cash-were used. These expenditures are shifted into other items of consumption expenditures. This 7 percent effect on participant food consumption is similar to the findings for the U.S. by Brown, Johnson, and Riyek (1982), who estimate the effect of food stamps on food consumption expenditures with income levels held constant, although once again the methodology used is questionable.

TABLE 3

Simulated Effect on Key Variables of Cash-Out of Food Stamp

Benefits Under Present Funding Levels

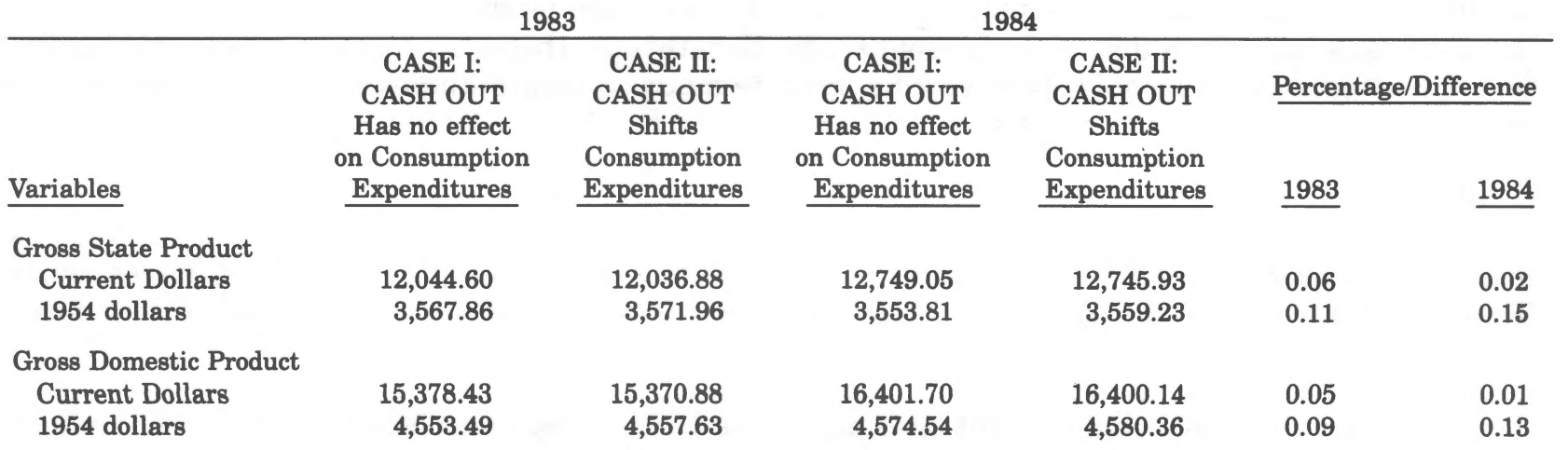


TABLE 3 (continued)

Simulated Effect on Key Variables of Cash-Out of Food Stamp

Benefits Under Present Funding Levels

\begin{tabular}{|c|c|c|c|c|c|c|}
\hline \multirow[b]{2}{*}{ Variables } & \multicolumn{2}{|c|}{1983} & \multicolumn{2}{|c|}{1984} & & \\
\hline & $\begin{array}{c}\text { CASE I: } \\
\text { CASH OUT } \\
\text { Has no effect } \\
\text { on Consumption } \\
\text { Expenditures } \\
\end{array}$ & $\begin{array}{c}\text { CASE II: } \\
\text { CASH OUT } \\
\text { Shifts } \\
\text { Consumption } \\
\text { Expenditures } \\
\end{array}$ & $\begin{array}{c}\text { CASE I: } \\
\text { CASH OUT } \\
\text { Has no effect } \\
\text { on Consumption } \\
\text { Expenditures } \\
\end{array}$ & $\begin{array}{c}\text { CASE II: } \\
\text { CASH OUT } \\
\text { Shifts } \\
\text { Consumption } \\
\text { Expenditures } \\
\end{array}$ & Percen & $\underline{1984}$ \\
\hline \multicolumn{7}{|l|}{ Personal } \\
\hline Current Dollars & $12,234.39$ & $12,231.67$ & $12,919.07$ & $12,916.38$ & 0.02 & 0.02 \\
\hline 1954 dollars & $3,508.21$ & $3,512.20$ & $3,505.83$ & $3,509.91$ & -0.11 & -0.12 \\
\hline \multicolumn{7}{|l|}{ Employment } \\
\hline Thousand Employed & 776.52 & 776.06 & 775.43 & 774.97 & 0.06 & 0.06 \\
\hline \multicolumn{7}{|l|}{ Personal Consumption } \\
\hline Current Dollars & $12,445.68$ & $12,441.60$ & $13,226.46$ & $13,222.10$ & 0.03 & 0.03 \\
\hline 1954 dollars & $3,568.80$ & $3,572.50$ & $3,589.23$ & $3,592.97$ & -0.10 & -0.10 \\
\hline \multicolumn{7}{|l|}{ Government Revenues } \\
\hline Current Dollars & $2,029.10$ & $2,027.83$ & $2,132.14$ & $2,131.22$ & 0.06 & 0.04 \\
\hline \multicolumn{7}{|l|}{ Imports } \\
\hline Current Dollars & $15,607.68$ & $15,607.68$ & $16,778.15$ & $16,774.90$ & 0.00 & 0.02 \\
\hline 1954 dollars & $3,602.24$ & $3,600.57$ & $3,679.37$ & $3,677.01$ & 0.05 & 0.06 \\
\hline
\end{tabular}

The results of the cash-out simulation are presented in tables 3 and 4 . When recipients treat bonus income from food stamps or from food checks in the same manner, the values of the variables are those presented earlier for present funding levels. In the case where cash-out is assumed to cause a shift away from food in consumption expenditures, some changes occur in key variables. As can be seen from the

TABLE 4

Simulated Impact of Cash-Out on

Personal Consumption Expenditures

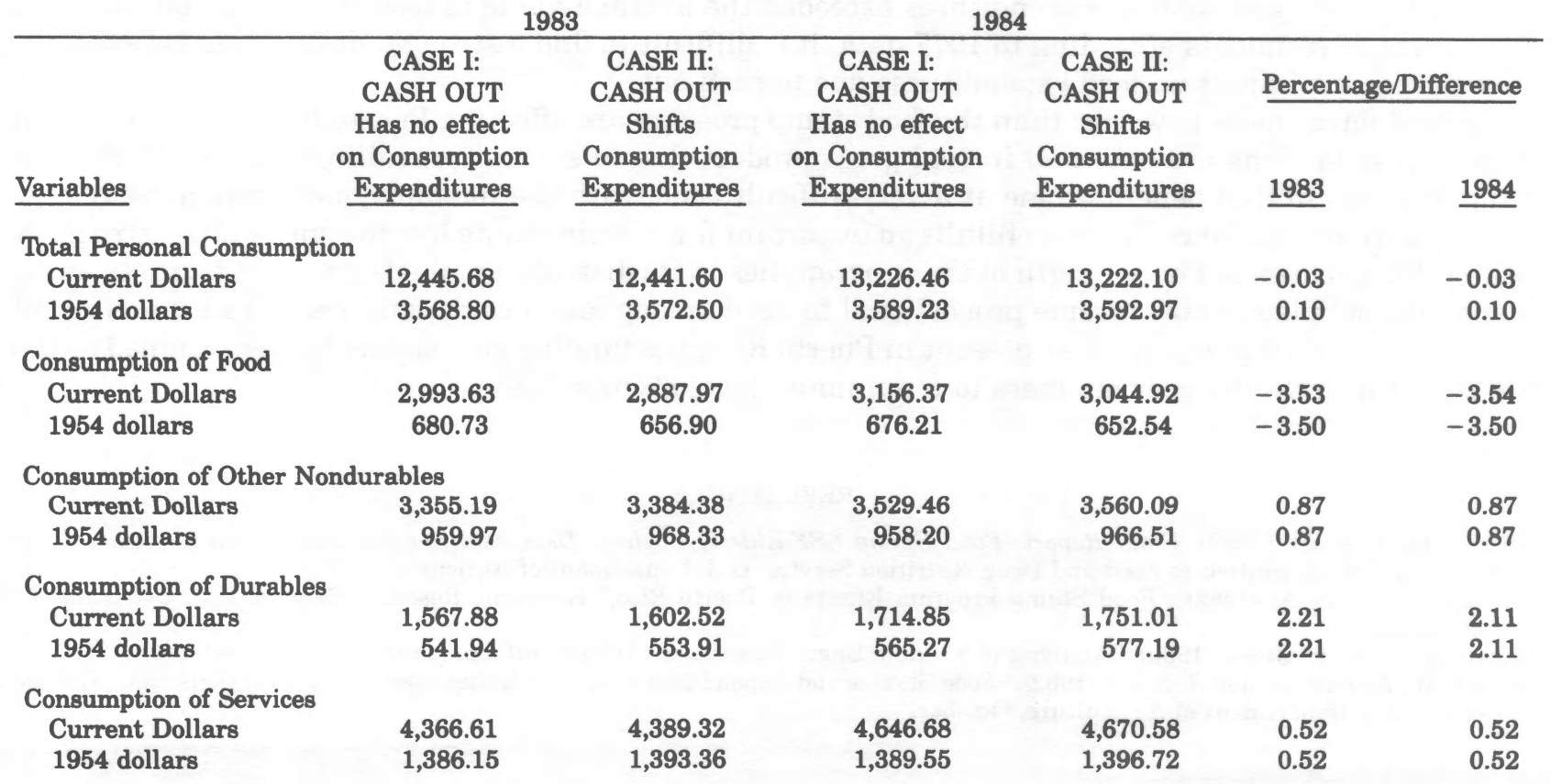


tables, gross product is scarcely affected, although a slight drop is reported for both years. Government revenues and employment also register apparent falls, while personal income rises in real terms. Although consumption is unaffected by assumption, there is a small increase in real terms due to the change in employment and personal income caused by the shift in the composition of demand (see below).

Table 4 presents the changes in consumption expenditures that occur under the assumed 3.5 percent shift from food into other consumption categories. The largest increase is in the consumption of durables, followed by increases in nonfood nondurables, and services: a not-unexpected pattern.

In brief, then, simulation results of the effect of cash-out indicate that within the most likley range of results, the impact on gross state product and employment is either nonexistent or small and negative. The most important effect, namely the effect on the consumption of food and basic necessities, is not predicted by this simulation experiment. Rather reliance was placed on other studies and data available in answering that question. Although there is conflicting evidence, it seems most plausible that the switch from food stamps to check has had little impact on food purchases of recipient families. On the other hand, since the average income of low-income Puerto Rican families has been reduced, the importance of each dollar of food assistance in maintaining minimum nutrition levels among the poor has doubtless increased.

\section{Conclusion}

The findings of the simulation experiments presented in this study confirm the importance of the food stamp program in sustaining personal consumption and show that the reductions in funding levels enacted since 1982 have an impact equivalent to that of a mild recession-the real level of gross state product falls by about 1 percent in 1983 and 1984 as a result of the funding cuts. The effect on personal consumption and on food expenditures are greater-an aggregate drop in food consumption of 2.2 percent was estimated for 1984, and among the lower-income half of the population food expenditures fall by an even greater percentage. The model does not make any estimates of the distributional impact of these cuts, but nutrition levels among the poorest persons dependent upon food assistance are likely to be affected as inflation erodes the purchasing value of benefits over time.

Based on the evidence available, it does not appear that the switch from food stamps to checks is likely to affect expenditure pattern as much as the reduction in benefits. Our simulation results indicate that the cash-out of food stamp benefits has had little effect on key aggregate economic variables: simulation experiments were based on two plausible, yet conflicting, assumptions regarding consumer reaction to the cash-out of food benefits. Whether or not the switch to checks from coupons has in fact changed family expenditure preferences, however, can only be determiend via empirical data not available at this time. Since weekly food expenditures exceeded the average value of food stamps $(\$ 9.65)$ for about 90 percent of recipients according to 1977 data, it is difficult to find a strong a priori basis for expecting any significant impact on food expenditures due to cash-out.

Several forces more powerful than the food stamp program are affecting Puerto Rico's economy at this time and reductions are expected in real gross product due to several prevailing negative influences. Thus the cuts in food benefits come at a very difficult time, with the unemployment rate already high. The Nutrition Assistance Program fulfills an important function in aiding low-income families struggling with falling incomes. The strength of the program lies in its distributional effects-that is, in its ability to provide supplementary income proportional to need among low-income families. Given the vital role food assistance programs have at present in Puerto Rico, the funding cuts should be re-examined so that we do not deprive the poor of access to a minimum level of nutrition.

\section{REFERENCES}

Blanchard, L. et al. (1982). Final Report-Food Stamp SSE/Elderly Cashout Demonstration Evaluation. Mathematica Policy Research, Inc., submitted to Food and Drug Nutrition Service, U.S. Department of Agriculture.

Blanciforti, Laura A. (1982). "Food Stamp Program Effects in Puerto Rico," Economic Research Service, U.S. Department of Agriculture.

Blaylock, J. and R. Green (1980). "Analysis of Flexible Engle Functions," Agicultural Economics Research, October.

Brown, M., A. Johnson and R. Riyek (1982). "Food Stamps and Expenditure Patterns: A Statistical Analysis." Consumer Nutrition Center, U.S. Department of Agriculture, October. 
Chai, J.C., J. Teitelbaum and G. Horowitz (1982). An Analysis of the 1977 Puerto Rican Food Consumption Survey with Emphasis on the Effects of Food Programs. Economic Analysis Staff, Food and Nutrition Service, U.S. Department of Agriculture, April 2.

Chen, J.S. and S.R. Johnson (1982). "Food Stamp Program Participation and Food Cost: A Simultaneous Equations Analysis With Qualitative and Continuous Dependent Variables," USDA.

Fregre, Jorge (1979). El Modelo Economic de Puerto Rico, Interamerican University Press, San Juan.

Hill, Marianne (1982). "The Nutrition Assistance Program in Puerto Rico: Present Impact and Proposed Changes," Puerto Rico Business Review, Government Development Bank, San Juan, July-August.

Lane, Sylvia (1982). The Food Stamp Program, unpublished paper, Department of Agricultural Economics, University of California at Davis.

Mann, Arthur J. "Economic Development, Income Distribution, and Real Income Levels: Puerto Rico, 1953-1977," Review of Social Economy, April, 1981.

Nelson, P.E. and J. Perrin (1976). Economic Effects of the U.S. Food Stamp Program, Calendar Year 1972 and Fiscal Year 1974. Agricultural Economic Report No. 331, Economic Research Service, U.S. Department of Agriculture, July.

Smallwood, D. and J. Blaylock (1982). "Analysis of Food Stamp Program Participation and Food Expenditures," Economic Research Service, U.S. Department of Agriculture, August 10.

Southworth, H.S. (1945). "The Economics of Public Measures to Subsidize Food Consumption," Journal of Farm Economics, February.

Udall, Alan T. (1981). "The Reagan Budget Cuts and Federal Funding to Puerto Rico," Puerto Rico Business Reivew, Government Development Bank, San Juan, October. 